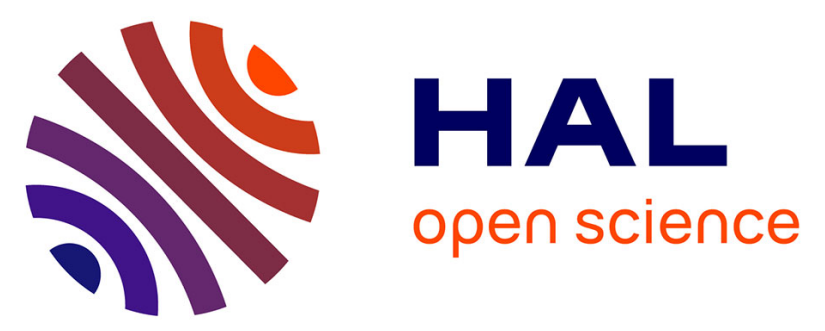

\title{
Response of bedrock channel width to tectonic forcing: Insights from a numerical model, theoretical considerations and comparison with field data
}

\author{
Jens M. Turowski, Dimitri Lague, Niels Hovius
}

\section{- To cite this version:}

Jens M. Turowski, Dimitri Lague, Niels Hovius. Response of bedrock channel width to tectonic forcing: Insights from a numerical model, theoretical considerations and comparison with field data. Journal of Geophysical Research: Earth Surface, 2009, 114 (F3), pp.F03016. 10.1029/2008JF001133 . insu-00573329

HAL Id: insu-00573329

https://hal-insu.archives-ouvertes.fr/insu-00573329

Submitted on 1 Apr 2016

HAL is a multi-disciplinary open access archive for the deposit and dissemination of scientific research documents, whether they are published or not. The documents may come from teaching and research institutions in France or abroad, or from public or private research centers.
L'archive ouverte pluridisciplinaire HAL, est destinée au dépôt et à la diffusion de documents scientifiques de niveau recherche, publiés ou non, émanant des établissements d'enseignement et de recherche français ou étrangers, des laboratoires publics ou privés. 


\title{
Response of bedrock channel width to tectonic forcing: Insights from a numerical model, theoretical considerations, and comparison with field data
}

\author{
Jens M. Turowski, ${ }^{1,2}$ Dimitri Lague, ${ }^{3}$ and Niels Hovius ${ }^{1}$ \\ Received 6 August 2008; revised 7 May 2009; accepted 19 May 2009; published 22 August 2009.
}

[1] The morphology of bedrock river channels is controlled by climatic and tectonic conditions and substrate properties. Knowledge of tectonic controls remains scarce. This is partly due to slow tectonic rates and long response times of natural channels and partly due to the difficulty in isolating and constraining tectonic forcing conditions in the field. To study the effect of tectonic forcing on channel geometry, we have developed a numerical model of the cross-sectional evolution of a detachment-limited channel. Its predictions are matched by an analytical model based on the assumption of the minimization of potential energy expenditure. Using these models, we illustrate how local tectonics can alter the observed width-discharge scaling and discuss published field data in light of our findings. Except for one case, the models fail to correctly describe field observations of well-constrained cases. This implies that the shear stress/stream-power family of models is too simple to describe the behavior of natural channels. Additional complexities such as sediment effects and discharge variability exert a strong control on channel morphology and need to be taken into account in the modeling of channel dynamics and steady state.

Citation: Turowski, J. M., D. Lague, and N. Hovius (2009), Response of bedrock channel width to tectonic forcing: Insights from a numerical model, theoretical considerations, and comparison with field data, J. Geophys. Res., 114, F03016, doi:10.1029/

2008JF001133.

\section{Introduction}

[2] Bedrock river channels play an important role in active landscapes: fluvial processes drive erosion by undercutting hillslopes and evacuating the products of mass wasting to depositional basins [Whipple, 2004]. Fluvial erosion rates and the channel's ability to transport sediment are strongly dependent on the channel geometry, namely, its bed slope and cross-sectional shape. Bedrock channel geometry is thought to evolve toward a unique steady state configuration, in which the vertical erosion rate matches the rate of rock uplift or baselevel lowering [e.g., Stark, 2006; Tucker and Whipple, 2002; Whipple and Tucker, 1999; Wobus et al., 2006]. This steady state is expected to be determined by local boundary conditions, which can be classed into four broad categories: (1) climate and discharge conditions including the mean and the variability of discharge [e.g., Craddock et al., 2007; Lague et al., 2005a; Snyder et al., 2003b; Stark, 2006; Wobus et al., 2006; Wohl and Merritt, 2001]; (2) substrate properties such as rock strength [e.g., Jansen, 2006; Montgomery, 2004; Montgomery and Gran, 2001; Wohl and David, 2008];

\footnotetext{
UK.

${ }^{1}$ Department of Earth Sciences, University of Cambridge, Cambridge,

${ }^{2}$ WSL Birmensdorf, Birmensdorf, Switzerland.

${ }^{3}$ Géosciences Rennes, UMR 6118, CNRS, Rennes, France.
}

Copyright 2009 by the American Geophysical Union. 0148-0227/09/2008JF001133
(3) river sediment load including the amount and variability of sediment supply and its grain size distribution [e.g., Cowie et al., 2008; Finnegan et al., 2007; Hancock and Anderson, 2002; Johnson and Whipple, 2007; Shepherd, 1972; Sklar and Dietrich, 2004; Turowski et al., 2008a, 2008b]; and (4) tectonic forcing [Amos and Burbank, 2007; Duvall et al., 2004; Harbor, 1998; Humphrey and Konrad, 2000; Lavé and Avouac, 2001; Pearce et al., 2004; Snyder et al., 2003a; Tomkin et al., 2003; Turowski et al., 2006; Whittaker et al., 2007a, 2007b]. While the effect of discharge has been studied extensively in theory and in the field, much needs to be learned about the other three groups. Because there have been several recent field studies and at least some reliable field data is available, we concentrate on the effects of tectonic forcing.

[3] Erosion rates are often modeled as a function of shear stress [e.g., Howard, 1994; Howard and Kerby, 1983; Lague et al., 2005a; Seidl and Dietrich, 1992; Sklar and Dietrich, 2004; Whipple and Tucker, 1999; Whipple et al., 2000]. For a given discharge, flow velocity and flow depth are higher in narrower and steeper channels, which in turn increase shear stress on the channel. Hence, in general it is assumed that in response to increased tectonic uplift the channel width is reduced, and/or the slope of the channel bed is increased. While slope response has been investigated in many studies [e.g., Gasparini et al., 2006; Lague et al., 2005a; Sklar and Dietrich, 2006; Whipple and Tucker, 1999, 2002], few theoretical and experimental, and only a 
handful of field studies, have dealt with the response of bedrock channel width to tectonic forcing.

[4] In this paper we demonstrate how local tectonics can alter the observed width-discharge scaling of a steady state channel, using a numerical model of cross-sectional evolution of a detachment-limited channel. We show that the model results are closely traced by an analytical model based on the assumption of the minimization of potential energy expenditure. We discuss published field data in the context of these two models. We start by reviewing recent field evidence and theories put forward to explain the sensitivity of channel geometry to uplift rate. Then we will describe the numerical model framework and the derivation of the analytical and compare the results. Finally, we will discuss published field data in light of the models' predictions.

\subsection{Observed Relationships Between Channel Width and Uplift Rate}

[5] Most field studies of the geometric response of bedrock channels to differing rock uplift rates have reported only a few data points and produced conflicting results. For example, Snyder et al. [2003a] found no significant difference in the width of channels along the Mendocino Triple Junction in California, USA, in zones with contrasting uplift rates but otherwise comparable attributes (including drainage area), but the channel bed slope was found to have adjusted to differences in tectonic forcing. The Clearwater River, WA, USA, which is thought to be in a steady state, shows a typical width-area scaling relationship following a power law with an exponent of 0.42 , despite a strong longstream gradient in incision rate [Pazzaglia and Brandon, 2001; Tomkin et al., 2003]. Whittaker et al. [2007a] reported an approximately constant width of the Rio Torto channel over four kilometers immediately upstream of the Fiamignano fault in the central Appenines, Italy, despite a likely gradient in rock uplift rate [Roberts and Michetti, 2004] and the doubling of the drainage area at a confluence within the studied river section. However, Whittaker et al. [2007a] interpreted this channel to be undergoing a transient response to an increase in fault slip rate about one million years ago. In contrast, the Bagmati River in the Siwalik Hills in Nepal [Lavé and Avouac, 2001] has responded to increased rock uplift by narrowing the channel, but it has a constant channel slope across an active fault block with strong rock uplift gradients. Finally, the Bakeya River in the Siwalik Hills in Nepal [Lavé and Avouac, 2001] and channels in the Santa Ynez Mountains, California, USA [Duvall et al., 2004] have responded to increased rock uplift rates by changing both width and slope. Examples from alluvial rivers further add to this kinematic panoply. Harbor [1998] reported that the alluvial Sevier River, Utah, USA, has decreased its width and increased its water surface slope in response to increased uplift rate, while Pearce et al. [2004] found that ephemeral streams crossing active folds in the San Bernadino Mountains, California, USA, adjusted slope, channel pattern, and flow width and depth under changing tectonic conditions. These examples illustrate that large-scale roughness (such as bed forms, large boulders or bars) may have an important influence on channel morphology, an aspect that has not been studied for bedrock channels. In summary, it seems that bedrock river channels can respond to changes in rock uplift rate in at least three ways, namely, by adjustments in (1) flow width, (2) channel slope, and (3) both.

[6] To shed light on the relative roles of slope and width adjustment to tectonic forcing, Turowski et al. [2006] studied microchannels cutting through cohesive material in an experimental landscape. With increasing uplift rate, the slope of the experimental channels increased linearly, while the channel width decreased down to a steady minimum value. Thus, the experimental channels reproduced two of the three response modes observed in nature: at low uplift rates both slope and width adjusted, and at high uplift rates changes were by slope response only. The minimum channel width was attributed to the shear stress on channel walls, which increases as the channel narrows, until a steady state is reached.

[7] With a similar motivation, Amos and Burbank [2007] surveyed several paleochannels crossing the active Ostler fault zone in southern New Zealand. They measured differential erosion from remnant terraces, which they assumed to reflect the changing rock uplift rate across the fault. In general, channel bed slopes were steeper in regions with higher uplift rates, while the channel width was smaller. However, at high uplift rates, the channel width reached a minimum value and was insensitive to further increases of uplift rates. Although these streams flowed through loose material, Amos and Burbank [2007] argued that channel behavior may have been detachment-limited, as they were actively eroding and had cut to a depth of several times their width after faulting started. Therefore, Amos and Burbank [2007] considered these channels to be good analogies of bedrock channels. The model best fitting their observations is an initial narrowing of the channel, and subsequent steepening, thus separating the cross-sectional response from the long-profile response in time. Although Amos and Burbank [2007] reported a convergence with the experimental results of Turowski et al. [2006], their data can also be interpreted with a power law dependency of width on differential incision (Figure 1 and Table 1).

[8] Although Lavé and Avouac [2001] did not report a functional relationship between valley width and uplift rate for the Bakeya and the Bagmati Rivers, the published data can be used to obtain such a relationship (Figure 2). For the Bakeya, drainage area is near constant over the section at $\sim 320 \mathrm{~km}^{2}$, while the Bagmati $\left(\sim 2800 \mathrm{~km}^{2}\right)$ is joined by a tributary in middle of the studied reach. Along the Bagmati the incision rates vary by a factor of two, over which the channel width does not exhibit a consistent pattern, while the channel width of the Bakeya systematically drops by a factor of about six over a sevenfold increase of incision rate. The majority of this drop occurs at incision rates between $\sim 2 \mathrm{~mm} / \mathrm{a}$ to $8 \mathrm{~mm} / \mathrm{a}$. In this river, too, channel width and incision rate can be related by a power law.

[9] Whittaker et al. [2007b] reported channel characteristics of several streams crossing active faults in the central Apennines, Italy. Although they did not report functional relationships between width and uplift rate, downstream distance can be used as a proxy for uplift rate, as the variation of uplift rate is thought to be monotonic along the stream (Figure 3). In the case of the Valleluce, channel width closely follows what is expected from simple scaling laws with drainage area, and increasing uplift rate in the downstream direction does not seem to affect channel 


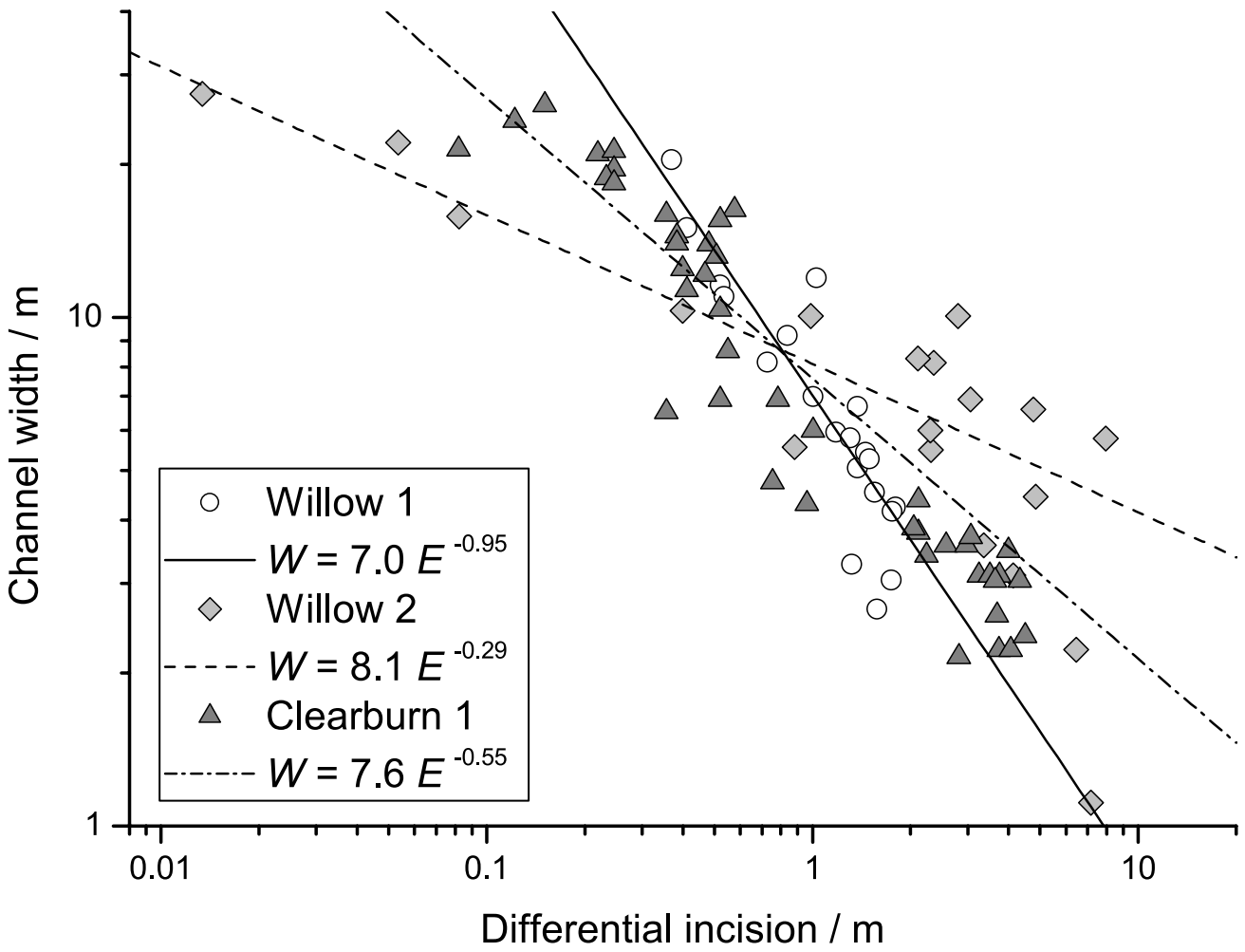

Figure 1. Channel width for the paleochannels of the Willow and Clearburn Creeks, New Zealand, as a function of differential incision (data digitized from Amos and Burbank [2007]). Power law interpretations describe the data well. Clearburn 2 and 3 have been omitted for clarity but give similar results.

width. The Fosso Tascino shows a systematic variation in channel width, with larger widths than expected from simple scaling with drainage area in the middle of the studied stretch (kilometers 5-7) and smaller width elsewhere (Figure 3), despite approximately constant block uplift. Other parameters thought to influence the channel width, such as the median grain size and substrate strength, do not change along the stream. Here, a power law relation linking width and uplift rate does not seem to describe observations.

\subsection{Theoretical Explanations}

[10] Early work on the sensitivity of channel geometry to uplift rate has focused on channel slope alone, starting from a simple detachment-limited mass balance and a stream- power type law for bedrock incision. Since the system of equations is not closed, an auxiliary assumption is needed to arrive at conclusions (see section 4.1 for more details). Initially, a simple typical hydraulic scaling of channel width with discharge was assumed [e.g., Whipple and Tucker, 1999], in which channel width was by definition insensitive to uplift rate. More recently, Finnegan et al. [2005] derived an implicit dependence of channel width on uplift rate through an explicit dependence of width on slope, based on the assumption that the width-to-depth ratio is constant for a given channel type. This assumption was supported by the work of Wobus et al. [2006, 2008], who described a model of a freely developing cross section of a detachmentlimited channel. Moreover, Finnegan et al.'s [2005] widthslope scaling equation is more accurate in predicting

Table 1. Channel Width as a Function of Incision Rate

\begin{tabular}{|c|c|c|c|}
\hline Channel & Steady State? & Power Law & Source \\
\hline Clearburn 1 & no & $W \sim E^{-0.55}, \mathrm{R}^{2}=0.84$ & Amos and Burbank [2007] \\
\hline Clearburn 2 & no & $W \sim E^{-0.91}, \mathrm{R}^{2}=0.95$ & Amos and Burbank [2007] \\
\hline Clearburn 3 & no & $W \sim E^{-1.14}, \mathrm{R}^{2}=0.84$ & Amos and Burbank [2007] \\
\hline Willow 1 & no & $W \sim E^{-0.95}, \mathrm{R}^{2}=0.86$ & Amos and Burbank [2007] \\
\hline Willow 2 & no & $W \sim E^{-0.29}, \mathrm{R}^{2}=0.90$ & Amos and Burbank [2007] \\
\hline Bagmati & yes & no clear trend & Lavé and Avouac [2001] \\
\hline Bakeya & yes & $W \sim E^{-0.59}, \mathrm{R}^{2}=0.96$ (valley) & Lavé and Avouac [2001] \\
\hline Clearwater River & yes & $W \sim E^{-1.11}, \mathrm{R}^{2}=0.85$ (valley) $W \sim E^{-0.44}, \mathrm{R}^{2}=0.30$ (channel) & Tomkin et al. [2003] \\
\hline Rio Torto & no & insufficient data & Whittaker et al. [2007a] \\
\hline Fosso Tascino & yes & insufficient data & Whittaker et al. [2007b] \\
\hline Valleluce & yes & insufficient data & Whittaker et al. [2007b] \\
\hline
\end{tabular}




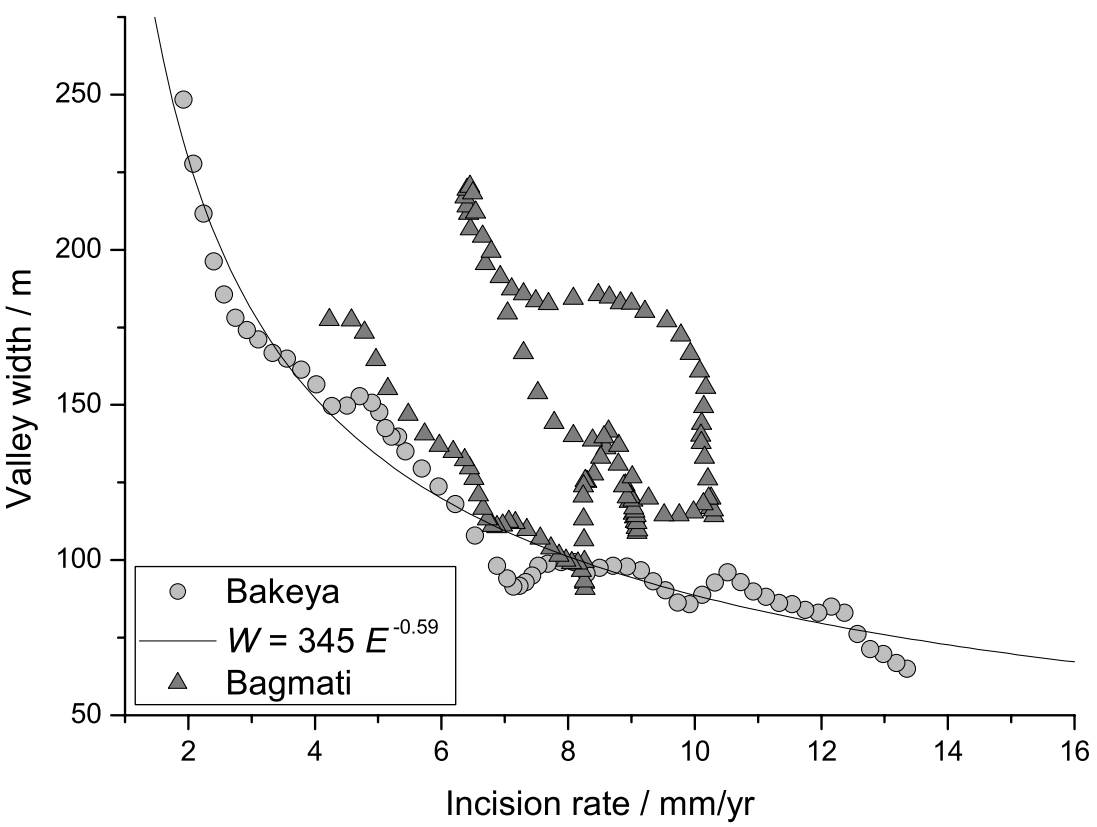

Figure 2. Valley width reported for the Bakeya and the Bagmati Rivers in the Siwalik Hills, Nepal, against incision rate surveyed from terrace deposits (data digitized from Lavé and Avouac [2001]). While the relationship for the Bakeya is well described by a power law, the lack of a trend is apparent for the Bagmati. The latter is joined by a tributary in the middle of the studied stretch, which could be responsible for the lacking trend in the width relationship.

channel width from observed slope and drainage area than a simple square root power law scaling of width with discharge [Finnegan et al., 2005; Whittaker et al., 2007a].
[11] Lague et al. [2005b] and Turowski et al. [2007] have derived functions for the dependence of channel width on uplift rate for simple shear stress type erosion models
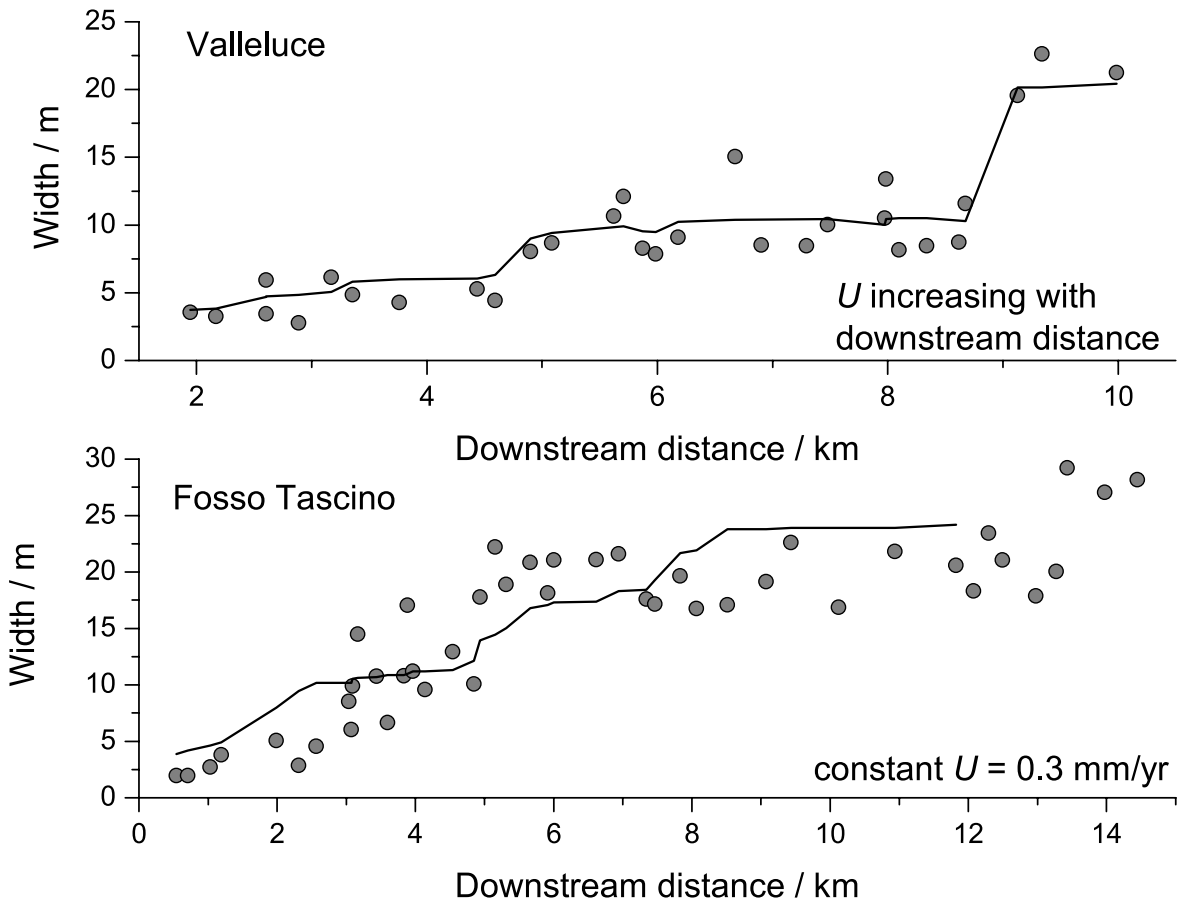

Figure 3. Channel width for the Fosso Tascino and the Valleluce Rivers, two channels crossing active faults in the central Apennines, Italy (data digitized from Whittaker et al. [2007b]). While for the Fosso Tascino the uplift rate is constant in the direction normal to the fault (uniform block uplift), for the Valleluce it increases in the downstream direction. The solid line gives the expected channel width if it scales with the square root of drainage area (see equation (8)). 
[e.g., Howard, 1994; Howard and Kerby, 1983; Seidl and Dietrich, 1992] and for the saltation-abrasion model, in which erosion is dependent on sediment flux [Sklar and Dietrich, 2004], assuming that slope is minimized with respect to width at steady state to close the system of equations. These models predict two distinct modes of channel response to tectonic forcing. At low uplift rates both channel slope and width are insensitive to increasing uplift rates (threshold-dominated), while at high uplift rates, they respond according to a power law, the exponent of which is essentially a function of the friction equation and the incision law used in the derivation (uplift-dominated). This exponent takes the value of $\sim-0.23$ for the simple shear stress erosion law and $\sim-0.5$ for the sediment supply dependent erosion law, with a slight dependence on drainage area in the latter case.

[12] In the following section we describe a numerical model of the evolution of the cross section of a detachmentlimited channel, which we will use subsequently to study tectonic forcing of detachment-limited channels.

\section{A Numerical Model of Channel Cross-Sectional Evolution}

\subsection{Setup}

[13] In a detachment-limited channel, the steady state channel morphology is a function of the local boundary conditions. This means that the channel parameters are essentially independent of what happens upstream or downstream and are only determined by discharge, uplift rate, and other conditions at the point of interest. Therefore, we have opted for a 2-D model simulating a single cross section. In this model, the channel boundary is discretized into a set of points, and the boundary can evolve in a continuous space. In each time step the model completes the following tasks:

[14] 1. Width and depth of the flow are calculated in the current cross section.

[15] 2. The shear stress for every point along the boundary is calculated.

[16] 3. The erosion rate for every point along the boundary is calculated and split into a horizontal and a vertical component.

[17] 4. The new position of every point in the boundary is calculated. This includes changes due to tectonic uplift.

[18] 5. Overhanging parts in the section are collapsed to the stable hillslope angle.

[19] 6. The density of points along the boundary is adjusted by adding additional nodes if the distance between two neighboring points exceeds a predefined threshold.

[20] In order to calculate the shear stress distribution and erosion rates, flow width and depth have to be known for a given discharge. Flow through the section has to satisfy two equations. One is the continuity equation

$$
Q=V A_{c}
$$

It ensures that the mass balance of water is correct. Here $Q$ is the discharge, $V$ the flow velocity averaged over the channel cross section, and $A_{c}$ the cross-sectional area of the flow. The other equation is a flow resistance equation, for which we choose the Manning equation [Manning, 1891], which is often used to model average flow velocity in mountain streams [e.g., Robert, 2003; Wohl, 2000]:

$$
V=\frac{1}{N} R_{h}^{2 / 3} S^{1 / 2}=\frac{1}{N} \frac{A_{c}^{2 / 3} S^{1 / 2}}{P_{w}^{2 / 3}} .
$$

Here $N$ is Manning's roughness coefficient, $S$ the channel bed slope, and $R_{h}$ is the ratio between cross-sectional area $A_{c}$ and wetted perimeter $P_{w}$, known as the hydraulic radius. Combining equations (1) and (2) to eliminate $V$ gives:

$$
\frac{A_{c}^{5 / 3} S^{1 / 2}}{N Q P_{w}^{2 / 3}}=1 .
$$

The product on the left-hand side of equation (3) can be calculated for any flow depth in the cross section, and depth is varied until equation (3) is satisfied to within an arbitrary accuracy (set to $0.1 \%$ for the model runs). Cross-sectional area and wetted perimeter are found by linearly interpolating between points along the boundary of the cross section. Mean flow velocity and hydraulic radius can be calculated from these values.

[21] The channel bed slope is calculated with reference to a fixed baselevel, set at a distance downstream, which is kept constant throughout a model run. The initial slope is set as a boundary condition. As the channel is eroded downward, the height above baselevel, and hence the channel bed slope, decreases. In this approach the evolution of the lowest point in the cross section is equivalent to the slope evolution. Therefore, our model can adjust both slope and width freely to the various forcing parameters.

\subsection{Shear Stress and Erosion}

[22] Boundary shear stress is defined as the product of the viscosity of the fluid and the velocity gradient perpendicular to the wall. It is a measure of the frictional force exerted on the wall by the fluid, and is often used to estimate wear and entrainment rates. The shear stress incision law [Howard, 1994; Howard and Kerby, 1983; Seidl and Dietrich, 1992] is based on the assumption that the erosion rate at any point can be expressed as a function of the boundary shear stress. It has been used in many studies [e.g., Lague et al., 2005a; Snyder et al., 2003a; Stark, 2006; Stock and Montgomery, 1999; Tucker and Whipple, 2002; van der Beek and Bishop, 2003; Whipple and Tucker, 1999; Wobus et al., 2006]. Whipple et al. [2000] and Sklar and Dietrich [2004] have formulated incision laws for various erosional processes as functions of boundary shear stress. Similarly, bed load transport equations have also been formulated as power law functions of shear stress [e.g., Bagnold, 1977; Fernandez Luque and van Beek, 1976; Meyer-Peter and Müller, 1948; Parker, 1990]. Here we assume that such descriptions are appropriate and that erosion rate can be written as a function of shear stress and material properties.

[23] There are accurate theoretical protocols for the calculation of shear stress along the boundary of a channel cross section of arbitrary shape [e.g., Diplas, 1990; Lundgren and Jonsson, 1964; Parker, 1978a, 1978b; Pizzuto, 1991; Vigilar and Diplas, 1997], but they are complex and numerically expensive. Simpler models have been developed for specific, fixed cross-sectional shapes [e.g., Knight and Patel, 


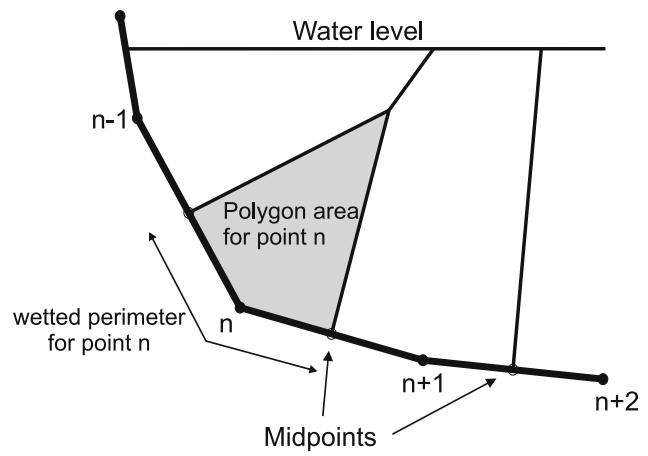

Figure 4. Illustration of the Merged Perpendicular Method (MPM): The cross section is represented by a set of points in a 2-D space (solid circles). The perpendicular bisector of each segment (starting at the midpoints depicted by open circles) of the cross section is traced until it meets another line. The two (or more) crossing lines are merged according to equation (4). This is repeated until the merged line crosses the water surface. The shear stress at point $\mathrm{N}$ is proportional to the area of the polygon (gray shaded) next to it divided by the local wetted perimeter (equation (5)).

1985; Knight et al., 1984]. Our model has a freely evolving cross section, and we have used a geometric model, the merged perpendicular method (MPM) by Khodashenas and Paquier [1999] to calculate local shear stresses. This method is a generalization of earlier geometric methods and has reproduced measured shear stress distributions in experimental, straight channels with deviations of less than $2 \%$ [Khodashenas and Paquier, 1999].

[24] In MPM, the cross section is discretized into a set of points. The perpendicular bisectors for each pair of neighboring points are found and traced into the cross section, until they meet another line or cross the water level (Figure 4). When two or more lines meet in a point, they are merged according to the formula:

$$
\mathbf{v}_{\mathbf{m}}=\sum_{\mathbf{n}} w_{\mathbf{n}} \mathbf{v}_{\mathbf{n}}
$$

Here $\mathbf{v}_{\mathbf{m}}$ is the vector along the resulting line, $\mathbf{v}_{\mathbf{n}}$ are the vectors along the lines to be merged, and $w_{\mathbf{n}}$ is the weight of line $\mathbf{n}$. Every perpendicular bisector starts with a weight of one, upon merging the weight of the resultant line is equal to the sum of the weights of the merged lines. The merged lines are again traced in a similar fashion, until no more crossings occur within the wetted channel. This method results in a polygon associated with each point of the cross section. The shear stress at a point is taken to be proportional to the area of the polygon divided by the length of the channel boundary along the edge of the polygon according to

$$
\tau_{i}=\rho g \frac{A_{i}}{P_{i}} S .
$$

Here $\rho$ is the density of water and $g$ the acceleration due to gravity, $\tau_{i}$ is the shear stress at point $i, A_{i}$ is the area of the corresponding polygon and $P_{i}$ the length of the sides of the polygon which are located along the channel boundary (the local wetted perimeter).

[25] The erosion rate at a point is calculated using a detachment-limited shear-stress incision law [Howard, 1994; Howard and Kerby, 1983; Seidl and Dietrich, 1992]:

$$
E=k_{e}\left(\tau-\tau_{c}\right)^{a} .
$$

[26] Here $E$ is the erosion rate, $\tau$ the bed shear stress, $\tau_{c}$ the critical shear stress for onset of erosion, $k_{e}$ describes the erodibility of the rock and $a$ is a dimensionless constant. Equation (6) is valid for $\tau>\tau_{c}$; otherwise $E=0$. Erosion is assumed to be normal to the bed surface at every point. As the cross section is modeled by a discrete set of points, it is difficult to establish the precise gradient of the channel bed. In our routine erosion at a point is assumed to be normal to the straight line connecting the two neighboring points.

\section{Results}

[27] We will now discuss the geometry of steady state cross sections under constant model conditions. Default values for fixed parameters are listed in Table 2. Other parameter values are given in the text. As we are mainly interested in functional relationships and scaling, we have picked parameter values as order of magnitude estimates (in particular the erodibility $k_{e}$ ). To explore the complete parameter space, some of the input values for uplift rate are unrealistically high.

[28] In the simulations a steady state channel geometry is said to be achieved when the channel geometry and hence the indicative channel response parameters (flow width, flow depth, bed slope, wetted perimeter, hydraulic radius and mean flow velocity) are constant in time, and vertical erosion matches rock uplift at any point in the cross section. Steady state sensu stricto only occurred in simulations with uplift rate $U=0$. Then, because of constant discharge, the section degrades until at every point in the section the shear stress is lower than the critical shear stress. In simulations with nonzero uplift rate erosion is nonzero. Occasionally, this leads to undercutting and slope failure, and widening of the channel. However, deviations from equilibrium values are always in the same direction (i.e., the channel always widens), are negligibly small (of the order of $0.01-0.2 \%$ ), and easily detectable in the time evolution of the system. Thus, they do not hamper the recognition of a steady state sensu lato. Furthermore, channel bed slope generally remains unaffected by slope failures and provides a means to check for steady state. Since steady state channel geometry is dependent only on local boundary conditions, the

Table 2. Default Values for Various Parameters Used in the Simulations

\begin{tabular}{ccc}
\hline Parameter & Meaning & Value \\
\hline$N$ & Manning's roughness coefficient & $0.035 \mathrm{~m}^{-1 / 3} / \mathrm{s}$ \\
$\tau_{c}$ & critical shear stress & $30 \mathrm{~Pa}$ \\
$k_{e}$ & erodibility constant & $8 \times 10^{-12} \mathrm{~kg}^{-\mathrm{a}} \mathrm{m}^{\mathrm{a}+1} \mathrm{~s}^{2 \mathrm{a}-1}$ \\
$a$ & exponent & 1 \\
$\Theta$ & stable angle & $40^{\circ}$ \\
$\Delta t$ & time step & 1 week \\
\hline
\end{tabular}


Table 3. Results for Simulations With $Q_{w}=50 \mathrm{~m}^{3} / \mathrm{s}$ and $U=1 \mathrm{~cm} / \mathrm{a}$ Starting From Different Initial Cross Sections and Channel Bed Slopes $^{\mathrm{a}}$

\begin{tabular}{|c|c|c|c|c|c|}
\hline Initial Slope & Initial Cross Section & Width (mm) & Depth (mm) & Mean Flow Velocity $(\mathrm{m} / \mathrm{s})$ & Slope \\
\hline 0.12 & $Q_{w}=50 \mathrm{~m}^{3} / \mathrm{s}, U=10 \mathrm{~cm} / \mathrm{a}$ & 8194 & 3247 & 2.43 & 0.00333 \\
\hline 0.1 & $Q_{w}=100 \mathrm{~m}^{3} / \mathrm{s}, U=0.1 \mathrm{~cm} / \mathrm{a}$ & 8198 & 3248 & 2.43 & 0.00333 \\
\hline 0.1 & $Q_{w}=200 \mathrm{~m}^{3} / \mathrm{s}, U=0.1 \mathrm{~cm} / \mathrm{a}$ & 8207 & 3246 & 2.43 & 0.00333 \\
\hline 0.025 & V-shaped & 8199 & 3249 & 2.43 & 0.00333 \\
\hline 0.0025 & V-shaped & 8196 & 3248 & 2.43 & 0.00333 \\
\hline 0.12 & V-shaped & 8199 & 3247 & 2.43 & 0.00333 \\
\hline
\end{tabular}

${ }^{\mathrm{a}}$ The top three initial cross sections are steady state cross sections for the stated conditions.

results presented here give generic functions describing the dependence of slope, width and other geometric parameters on boundary conditions, and not a specific scenario such as a channel in a uniform uplift field.

\subsection{Dependence on Initial Conditions and Model Setup}

[29] At the start of each run an initial cross section and channel bed slope are specified. For zero uplift rate $U=0$, steady state geometries were found to depend, occasionally, on these initial conditions. Once the channel cross section reaches a configuration with shear stresses below the erosion threshold, it cannot evolve further. This may happen for several channel geometries, and a meaningful steady state cannot then be reached. However, it is questionable whether detachment-limited conditions, which give rise to this model behavior, apply in systems without tectonic forcing. In light of this, we shall not further consider results from zero uplift runs. At nonzero uplift rates the channel bed slope will increase steadily when shear stresses are below the erosion threshold until erosion commences again. Then, the channel cross section can adjust to the boundary conditions completely. Consequently, initial conditions do not have an effect on runs with nonzero uplift rates (Table 3 ).

[30] In most model runs we have used an initial cross section with triangular shape, at two different spatial resolutions (one point every 10 or $50 \mathrm{~cm}$ across the channel), depending on discharge. To force short response times, the initial channel bed slope was generally set to a value larger than the steady state value. The value of the stable hillslope angle $\Theta$ did not have an effect on steady state channel geometry.

\subsection{Dependence on Discharge}

[31] The downstream development of channel bed slope, flow width, depth and mean velocity with accumulating discharge can be described by power law functions [Hack, 1957; Leopold and Maddock, 1953; Parker et al., 2007]:

$$
\begin{aligned}
& S=k_{s} Q^{-\theta} \\
& W=k_{w} Q^{\omega} \\
& D=k_{d} Q^{\delta} \\
& V=k_{v} Q^{\nu} .
\end{aligned}
$$

[32] Here $W$ is the channel width, $D$ is the channel depth, the $k$ values are dimensional parameters dependent on substrate properties and tectonic forcing, and $\theta, \omega, \delta$, and $\nu$ are dimensionless constants. Equations (8) to (10) are known as downstream hydraulic geometry relations and have been originally developed for alluvial channels [Leopold and Maddock, 1953]. For bedrock channels, equations (7) and (8) are generally thought to apply when the channel is in a steady state [Montgomery and Gran, 2001; Whipple, 2004]. Both $\theta$ (known as concavity index) and $\omega$ vary in the range of approximately $0.3-0.7$, with most commonly cited values of 0.5 for both alluvial and bedrock channels [Hack, 1957; Leopold and Maddock, 1953; Park, 1977; Whipple, 2004]. The relationships between steady state channel geometry and discharge predicted by the model for various uplift rates are shown in Figure 5. Exponent values are independent of uplift rate. Channel bed slope decreases with increasing discharge. The concavity index is $\theta=0.461$. All other channel parameters increase with increasing discharge. The exponent of the width-discharge relationship is equal to $\omega=0.461$, while $\delta=0.461$ and $v=0.077$.

\subsection{Response to Tectonic Forcing}

[33] The channel response to tectonic forcing shows two distinct domains (Figure 6): at low uplift rates (smaller $\sim 0.1 \mathrm{~cm} / \mathrm{a}$ for the parameter values given in Table 3; this corresponds to $\sim 2 \mathrm{~Pa}$ on Figure 6 ) the channel does not respond to changing uplift rate. All channel parameters are approximately constant in this region. For high uplift rates the tectonic control on the channel is strong: channel bed slope and mean flow velocity increase with increasing uplift rate, while width and depth decrease. Similar channel response is observed for the inverse of erodibility. In fact, using $U / k_{e}$ as a variable leads to a similarity collapse (Figure 6), and increasing uplift rate has the same effect as decreasing erodibility. If a power law is fitted to the varying part of the function, the exponents are around 1.1 to 1.2 for slope, -0.18 to -0.20 for width, -0.21 to -0.23 for depth and $\sim 0.41$ for velocity.

\section{Model Interpretation and Discussion}

4.1. General Considerations for 1-D Models of Channel

\section{Morphology}

[34] To interpret these results we consider simple 1-D models of steady state channel geometry. These models treat the cross-channel dimension parametrically. The constitutive equations for any 1-D model of channel morphology consist of the continuity equation (equation (1)), a flow 

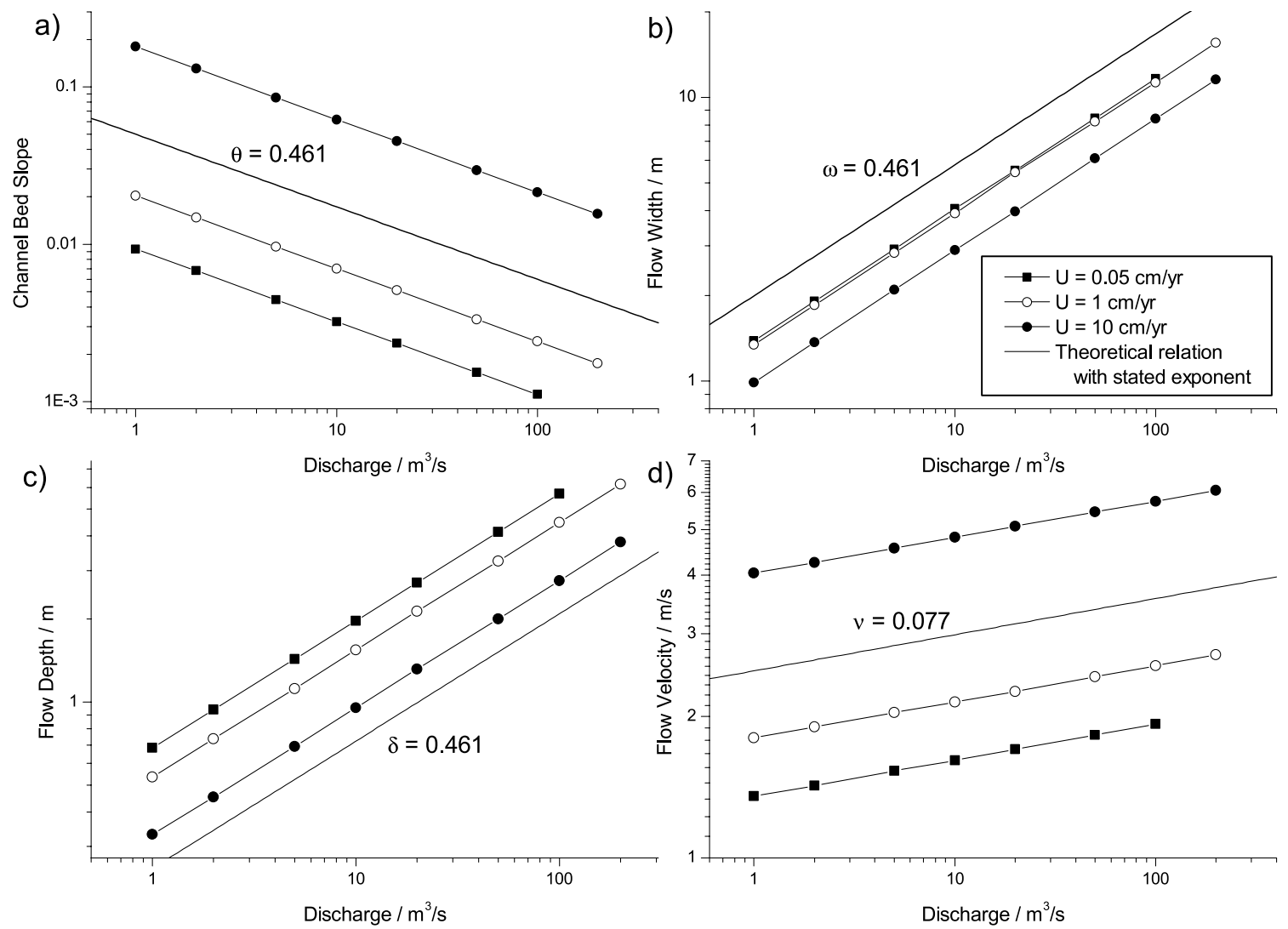

Figure 5. Steady state geometry parameters (a) slope, (b) width, (c) depth, and (d) velocity as functions of discharge for channels at various uplift rates. The power law exponents obtained from fits to the data are given on the plots for comparison (see equations (7)-(10), (17), and (18)).

resistance equation such as the Manning equation (equation (2)), the definition of the hydraulic radius:

$$
R_{h}=\frac{A_{c}}{P_{w}},
$$

and the DuBoys equation for shear stress:

$$
\tau=\rho g R_{h} S .
$$

Two further equations for the cross-sectional area and the wetted perimeter arise from an assumed channel shape. For example, for a rectangular channel these equations are:

$$
\begin{gathered}
A_{c}=W D, \\
P_{w}=2 D+W .
\end{gathered}
$$

The system can then be reduced to a single equation with three dependent parameters (slope, width and shear stress):

$$
N Q\left(2 \frac{\tau}{\rho g}-S W\right)+S^{-1 / 6} W^{2}\left(\frac{\tau}{\rho g}\right)^{5 / 3}=0
$$

Equation (15) or a similar equation forms the basis of any 1-D model of channel geometry. To close the system, two additional equations are necessary. One is an erosion law.
The other is an auxiliary assumption, that is an equation that is chosen essentially ad hoc, and without a sound theoretical basis. Previously used auxiliary assumptions include the empirical hydraulic geometry relation for channel width (equation (8)) [e.g., Sklar and Dietrich, 2006; Whipple and Tucker, 1999] and a constant width-todepth ratio [Finnegan et al., 2005]. We will now close the equation with an extremal hypothesis and show that the predictions of the resulting model closely traces the results of the numerical model.

\subsection{Comparison of the Numerical Model to an Analytical Model}

[35] The numerical model predicts two distinct modes of geomorphic response of a channel to tectonic forcing: at low uplift rates, the geometry is largely insensitive to increasing uplift rates, while at high uplift rates, the geometric variables change with uplift rate according to a power law. Similar behavior has been predicted by the analytical models proposed by Lague et al. [2005b] and Turowski et al. [2007]. Lague et al. [2005b] derived functions for slope and width of the channel at steady state with the auxiliary assumption that a detachment-limited channel minimizes its slope with respect to width:

$$
\frac{d S}{d W}=0
$$



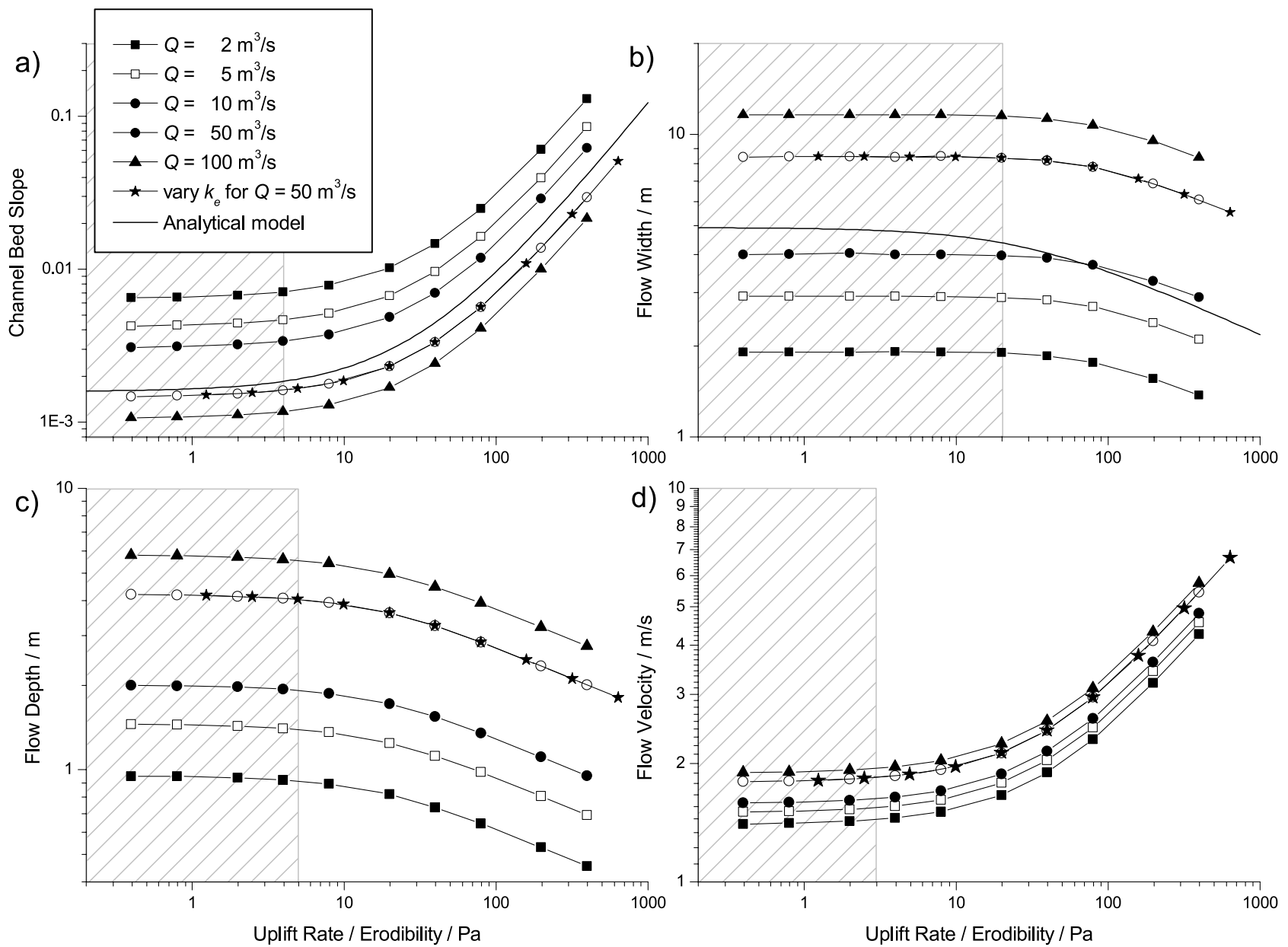

Figure 6. Steady state geometry parameters (a) slope, (b) width, (c) depth, and (d) mean flow velocity as function of uplift rate normalized by erodibility for channels at various discharges. The normalization leads to a similarity collapse of the two variables, as can be seen for the data for $Q=50 \mathrm{~m}^{3} / \mathrm{s}$. Solid lines show realizations of equations (17) and (18) for slope and width with $Q=50 \mathrm{~m}^{3} / \mathrm{s}$. Gray shading shows the approximate extent of the threshold-dominated region.

This assumption corresponds to the optimization of expenditure of potential energy, similar to what has been described for alluvial streams [e.g., Huang et al., 2004; Yang et al., 1981]. The resulting equations for slope and width are:

$$
S=C_{S}\left[\frac{\tau}{\rho g}\right]^{16 / 13}(N Q)^{-6 / 13}=C_{S}\left[\frac{\tau_{c}}{\rho g}+\frac{U}{\rho g k_{e}}\right]^{16 / 13}(N Q)^{-6 / 13},
$$

$$
W=C_{W}\left[\frac{\tau}{\rho g}\right]^{-3 / 13}(N Q)^{6 / 13}=C_{W}\left[\frac{\tau_{c}}{\rho g}+\frac{U}{\rho g k_{e}}\right]^{-3 / 13}(N Q)^{6 / 13}
$$

In equations (17) and (18), shear stress $\tau$ has been eliminated using the erosion law (equation (6)) and the steady state assumption $E=U$. Similar equations can be derived for depth and flow velocity. It can be shown that equations (17) and (18) are valid for rectangular, trapezoidal and power law cross-sectional geometries. The dimension- less parameters $C_{S}$ and $C_{W}$ set the absolute size of the section and depend on the chosen channel geometry. The functional form of equations (17) and (18), with the same input parameters as for the numerical model, is illustrated in Figure 7 . There is a close match of the predicted scaling exponents predicted by the numerical model and equations (17) and (18) (Table 4 and Figures 5 and 6).

[36] The difference between the numerical model and the analytical model described by equations (17) and (18) lies in the way shear stress is treated. While a single mean value is used in the analytical model, a nonuniform distribution is calculated in the numerical model. This does not affect the prediction of scaling exponents (the cross section adjusts such that the spatial distribution of shear stress is the same for the different formative discharges at steady state), but it is expected to cause a difference in the absolute value of the predicted geometrical parameters. The effect is best illustrated using the width-to-depth ratio $W / D$, which is predicted by the analytical model (equations (17) and (18)) to be constant $(W / D=2$ for rectangular cross sections). The numerical model predicts larger values of $W / D$ (approximately two to three), independent of discharge and boundary roughness, but dependent on uplift rate, critical shear 


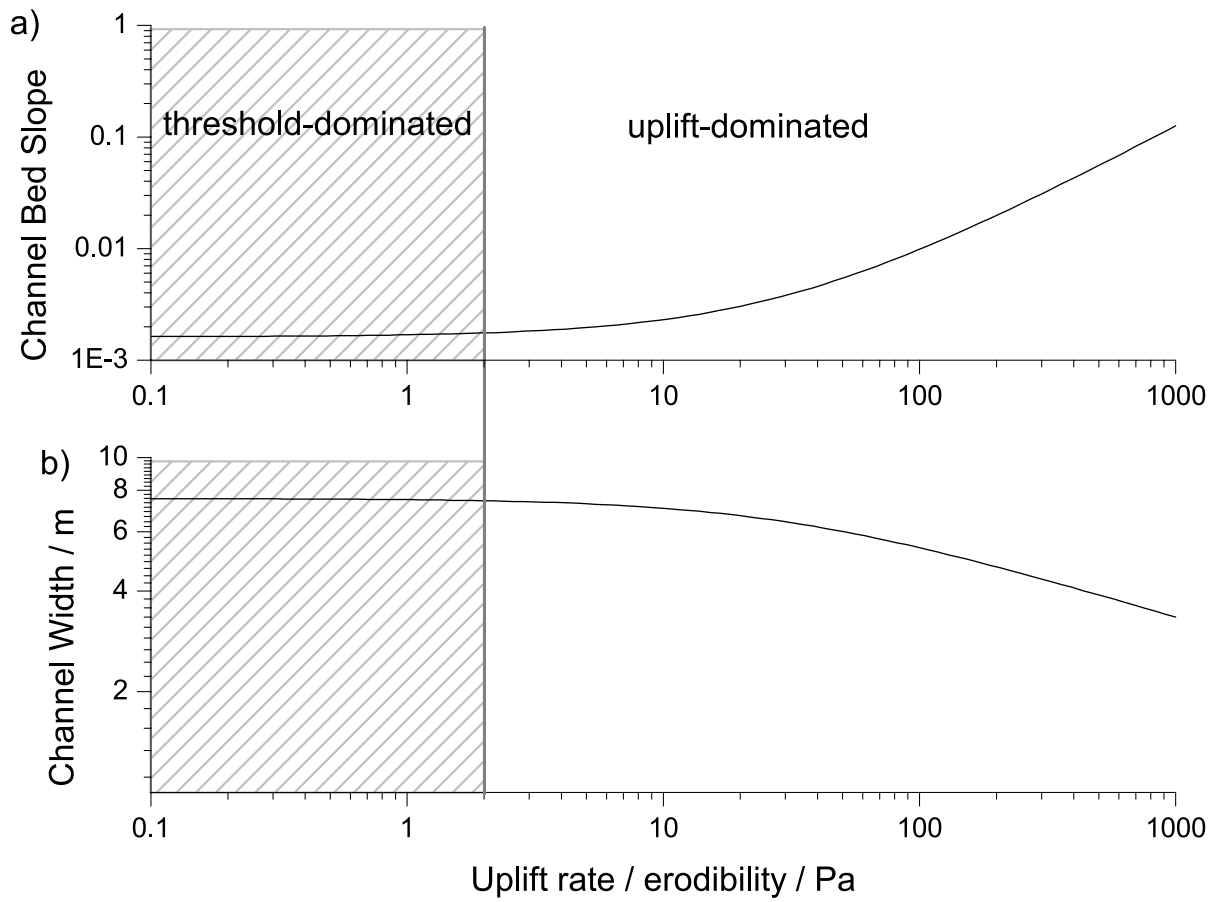

Figure 7. Functional form of (a) slope and (b) width response on tectonic uplift as predicted by equations (10) and (11) for a discharge $Q=50 \mathrm{~m}^{3} / \mathrm{s}$. In the threshold-dominated domain both width and slope are approximately independent of uplift rate. Gray shading shows the approximate extent of the threshold-dominated region, and the gray line at $U=0.1 \mathrm{~mm} / \mathrm{a}$ shows the approximate boundary between threshold- and uplift-dominated domains.

stress and erodibility (Figure 8). The cause of this variation is explained below.

[37] Using equations (17) and (18), we can now interpret the two modes of channel response to tectonic forcing. When the uplift rate is small, the term dependent on critical shear stress is larger than the term dependent on uplift rate:

$$
\tau_{c}>\frac{U}{k_{e}}
$$

and the latter can be neglected. Then, channel bed slope and width are approximately independent of tectonic forcing. Similarly, when

$$
\tau_{c}<\frac{U}{k_{e}}
$$

the threshold term can be neglected and width and slope are power law dependent on uplift rate. Turowski et al. [2007]

Table 4. Exponents of Discharge Relationship for Analytical Solution Using the Optimization of Potential Energy and Numerical Model for Constant Generating Discharge and Various Uplift Rates

\begin{tabular}{lcccc}
\hline \multicolumn{1}{c}{ Parameter } & Theory & $U=0.05 \mathrm{~cm} / \mathrm{a}$ & $U=1 \mathrm{~cm} / \mathrm{a}$ & $U=10 \mathrm{~cm} / \mathrm{a}$ \\
\hline Slope & 0.461 & 0.462 & 0.462 & 0.462 \\
Width & 0.461 & 0.460 & 0.461 & 0.462 \\
Depth & 0.461 & 0.461 & 0.460 & 0.461 \\
Velocity & 0.077 & 0.077 & 0.077 & 0.077 \\
Cross-sectional area & 0.923 & 0.922 & 0.923 & 0.923 \\
Wetted perimeter & 0.461 & 0.461 & 0.461 & 0.462 \\
Hydraulic radius & 0.461 & 0.462 & 0.462 & 0.462 \\
\hline
\end{tabular}

suggested the terms "threshold-dominated" and "upliftdominated" for the two modes of response.

[38] Note that the boundary between these domains is equal for slope and width in the analytical model $(\sim 2 \mathrm{~Pa}$ in both cases, Figure 7), while for the numerical model the boundary for width ( $\sim 20 \mathrm{~Pa}$, Figure $6 \mathrm{~b})$ is larger than for slope ( $\sim 4 \mathrm{~Pa}$, Figure 6a). Likewise, the domain boundaries for depths and velocity are at different values of relative uplift rate. These differences can be used to explain the variation of the channel width-to-depth ratio with uplift rate: the domain boundary is at a lower uplift rate for flow depth than for width. For high and low uplift rates the width-todepth ratio is predicted constant, in parallel to the analytical model. But at intermediate uplift rates the channel walls are in the threshold-dominated regime (i.e., width is not sensitive to uplift rate; Figure 6), while the bed slope progressively becomes uplift-dominated (slope increases with uplift rate; Figure 6). The spatial distribution of shear stress along the section varies with uplift rate, explaining the limitation of the analytical model which assumes a constant distribution independent of uplift rate. The prediction of a nonconstant width-to-depth ratio is thus a direct consequence of the inclusion of a threshold for incision in our model.

\subsection{Width-Slope Scaling and the Width-to-Depth Ratio}

[39] The predictions for the width-to-depth ratio deserve some further discussion. In our model, the width-to-depth ratio is independent of discharge and boundary roughness, but it increases slightly from about two to about three over the range of tested uplift rates. In addition, it varies with 

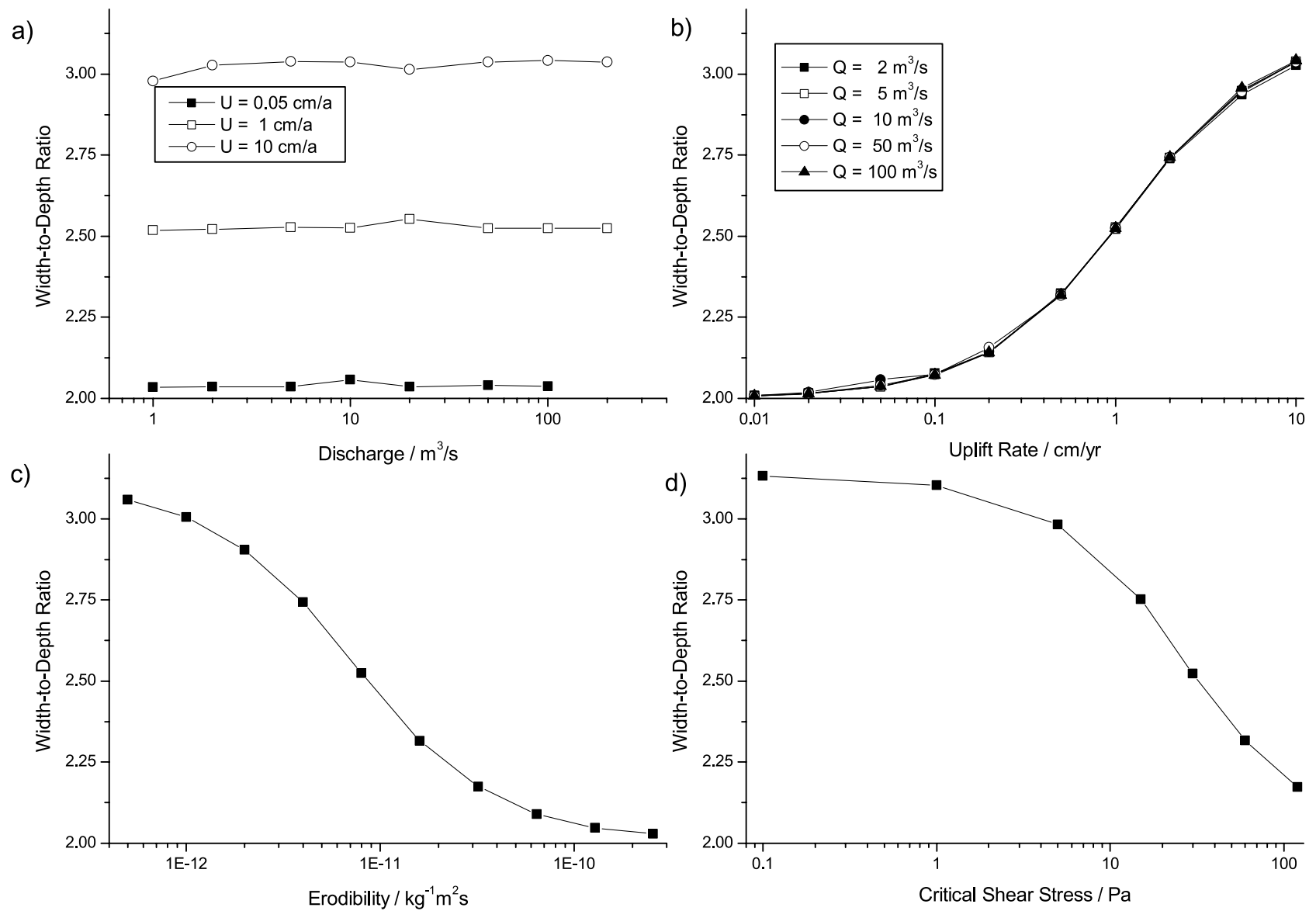

Figure 8. Width-to-depth ratio as a function of (a) discharge, (b) uplift rate, (c) erodibility, and (d) critical shear stress. The simulations for Figures $8 \mathrm{c}$ and $8 \mathrm{~d}$ were done at $Q=50 \mathrm{~m}^{3} / \mathrm{s}$ and $U=0.1 \mathrm{~mm} / \mathrm{a}$.

critical shear stress and erodibility $k_{e}$ (Figure 8 ). As outlined above, this is a direct result of the inclusion of an erosion threshold. On the basis of the assumption that the width-todepth ratio is constant for a given channel type, Finnegan et al. [2005] showed that channel width should be a power function of channel bed slope:

$$
W=\left[\frac{W}{D}\left(\frac{W}{D}+2\right)^{2 / 3}\right]^{3 / 8}(N Q)^{3 / 8} S^{-3 / 16}
$$

Similar dependencies have subsequently been reproduced by Wobus et al. [2006, 2008] with a model with freely adjusting cross section. Whittaker et al. [2007b] suggested an empirical equation with slightly different exponents to those in Finnegan et al.'s [2005] model. We can obtain a function similar to equation (21) from equations (17) and (18) by eliminating uplift rate. The equation for channel width reads then:

$$
W=C_{W} C_{S}^{3 / 16}(N Q)^{3 / 8} S^{-3 / 16}
$$

This is similar to equation (21) in the dependency of width on discharge and slope. As noted above, equations (17) and (18) result in constant width-to-depth ratios, the precise value of which depends on the channel geometry assumed in the calculation, thus converging with the auxiliary assumption of Finnegan et al.'s [2005] model. Because of the dynamic treatment of channel width, the width-to-depth ratio is variable in the numerical model. The assumption of constant width-to-depth ratio is not necessary to obtain a power law scaling between width and slope and is probably incorrect for natural channels [cf. Turowski et al., 2007; Wobus et al., 2008; Wohl and David, 2008].

\subsection{Comparison With Field Observations}

[40] In section 4.2, we have established that equations (17) and (18) describe the scaling of channel parameters with boundary conditions for steady state channel cross sections produced by the numerical model. We can thus use these equations for a comparison with available field data. In a typical field setting, both drainage area and uplift rate vary alongstream, and the downstream evolution of channel width can deviate considerably from the often cited square root relationship with drainage area (equation (8)). Because in the model the discharge control on channel width is stronger than the uplift control (scaling exponents are 6/13 and $-3 / 13$, respectively; equation (18)), a downstream reduction in width can only be achieved if uplift rate increases much more rapidly in the downstream direction than discharge. As an illustration, consider a setting where uplift rate varies systematically in the downstream direction. Since discharge increases in the downstream direction, 
uplift rate varies as a function of discharge, for example as a power law:

$$
U=c Q^{b}
$$

Then, equation (18) can be rewritten:

$$
W=C_{W}\left[\frac{\tau_{c}}{\rho g}+\frac{U}{\rho g k_{e}}\right]^{-3 / 13}\left(N\left(\frac{U}{c}\right)^{1 / b}\right)^{6 / 13} .
$$

Neglecting the threshold term in equation (24) to make the relationship easier to interpret (this is equivalent to considering the uplift-dominated domain), the width-uplift rate relationship can be written as:

$$
W \propto U^{\eta},
$$

where

$$
\eta=\frac{6}{13 b}-\frac{3}{13}
$$

Thus, in the uplift-dominated mode, equation (24) is an increasing function of $U$ for all $0<b<2$, and a decreasing function for all other cases. In most field studies of streams, channel width decreases as a function of incision rate (Table 1). This could imply either a strongly increasing uplift rate $(b>2)$ or a decreasing uplift rate $(b<0)$ in the downstream direction. Similarly, by eliminating uplift rate instead of discharge in equation (18), one obtains width as a function of discharge:

$$
W=C_{W}\left[\frac{\tau_{c}}{\rho g}+\frac{c Q^{b}}{\rho g k_{e}}\right]^{-3 / 13}(N Q)^{6 / 13}
$$

Neglecting the threshold term, equation (27) results in:

$$
W \propto Q^{\omega},
$$

where

$$
\omega=\frac{6}{13}-\frac{3 b}{13}
$$

This is similar to equation (8), with a scaling exponent dependent on the local variations of uplift rate. Equations (28) and (29) illustrate how local tectonics can modify the observed width-discharge scaling in steady state channels from what is expected purely from a width dependence on discharge. We will now discuss field cases in light of equations (24)-(29).

[41] In the reaches surveyed by Amos and Burbank [2007], the Clearburn and Willowbank channels were not joined by any tributaries and discharge can be assumed to be approximately constant. From equation (18), we would then expect channel width to decrease with incision rate according to a power law with an exponent of $-3 / 13$ $(\approx-0.23)$. The measured exponents of the width-incision rate relationship are much larger than this, with three values close to -1 and one each at -0.55 and -0.29 (Table 1). Hence, channel width decreases faster with incision rate than expected for a steady state channel. However, it needs to be born in mind that the measurements reflect a transient rather than a steady state. Amos and Burbank [2007] concluded that the channels narrowed before they steepened. The initially low channel gradient may have been the reason for the small width in comparison to the steady state scaling relationships expected from equation (24).

[42] In the Bakeya River, drainage area is approximately constant over the reach studied by Lavé and Avouac [2001]. Here too, the measured width-incision rate exponent $(-0.59)$ is much higher than expected for a detachmentlimited channel at steady state. The case is more complicated for the remaining field sites, where both discharge and uplift rate vary along the channel. For example, in the Bagmati River [Lavé and Avouac, 2001], a tributary joining the stream in the middle of the studied reach may be responsible for the lack of a trend between valley width and incision rate. In the Clearwater River [Tomkin et al., 2003], the measured width-incision rate exponent is $\eta=$ -0.44 for channel width and $\eta=-1.11$ for valley width. The measured incision rate is indeed a power function of the representative discharge, with a best fit exponent of $b=$ -0.62 . The values of $b$ and $\eta$ are related by equation (26) and the expected value of $\eta=-0.98$. This is reasonably close to the exponent derived from valley width.

[43] For the rivers studied by Whittaker et al. [2007a, 2007b] incision rate is not resolved along the channel and only some general information is available. Therefore, a power law exponent for the width-incision rate relationship cannot be derived. However, we can discuss these examples using drainage area as a proxy for discharge. For the Valleluce River [Whittaker et al., 2007b], the downstream evolution of channel width is well described by a power law function of drainage area, with a best fit exponent of 0.51 . Using equation (26), this implies that uplift rate decreases with increasing area according to a power law with an exponent of -0.21 . This contradicts what is known about local tectonics: the Valleluce crosses a tilting fault block and uplift rate increases in the downstream direction. Similarly, for the Fosso Tascino the width-area exponent of 0.78 implies an uplift-area exponent of -1.38 , despite the fact that the stream crosses a fault block with constant uplift.

[44] In summary, of the field cases documented in the literature, only the geometry of the Clearwater River can be explained to a reasonable extent within our model framework, if the valley width is used for computations. Tomkin et al. [2003] excluded shear stress type incision models (such as equation (6)) as inconsistent with their data. However, the additional assumptions they used to close the equations include for example the hydraulic geometry equation for channel width (equation (8)), with constant prefactor $k_{w}$ (in our models, $k_{w}$ is a function of uplift rate). If equation (18) is solved for $E$ (or equivalently, $U$ ), the strong dependence of incision rate on channel width in steady state channels becomes clear:

$$
E=\rho g k_{e} C_{W}^{13 / 3} \frac{(N Q)^{2}}{W^{13 / 3}}-k_{e} \tau_{c}
$$


This analysis shows that an adequate treatment of channel width in the model formulation can substantially change predictions for steady state geometry.

[45] Our model fails to predict the channel geometry of the other documented rivers. This could have several causes. First, it has been argued that bedrock erosion is often driven by the impact of moving sediment particles and that sediment supply should exert a fundamental control on incision rates and channel morphology [e.g., Johnson and Whipple, 2007; Sklar and Dietrich, 2004; Turowski et al., 2007]. Second, the variability of discharge is known to be a first order control on fluvial incision rates, especially when an erosion threshold is important [Lague et al., 2005a; Molnar, 2001; Molnar et al., 2006; Snyder et al., 2003b; Stark, 2006; Tucker, 2004]. In fact, Lague et al. [2005a] have demonstrated that for long return times of erosive events the threshold-dominated domain in the slope response disappears, and that slope depends instead on uplift rate according to a power law. Although Lague et al. [2005a] assumed in their derivation that channel width is independent of uplift rate, their work has shown that the erosion threshold and the variability of discharge together influence the rock uplift rate at which the transition occurs between the threshold-dominated domain and the upliftdominated domain. Turowski et al. [2008a] have demonstrated that in the Liwu River, Taiwan, the interplay of sediment supply and discharge variability sets the crosssectional channel geometry. There, extreme flood events, for instance typhoon-driven discharges, carry large sediment loads which protect the thalweg and enhance erosion on the channel walls. Converging results were found for other Taiwanese rivers [Turowski et al., 2008b]. Turowski et al. [2007] used an incision law dependent on sediment supply to derive equations for channel morphology, in which the scaling exponents vary considerably with the sediment supply situation. The failure of our model to adequately describe well-constrained field examples of channels thought to be in steady state implies that stream-power-type erosion laws are too simple to describe channel processes in most conditions, even if width variation is fully taken into account. Therefore, sediment effects on erosion and a realistic flood cycle should be included in future modeling attempts.

[46] Tomkin et al. [2003] explicitly considered the different roles of channel width and valley width. In the Clearwater River, the scaling relations of channel width with discharge, and of valley width with discharge are quite different, with a width-area scaling exponent of 0.76 for valley width and 0.42 for channel width. Using equation (24), the data from this river are consistent with our model if valley width is used, but not if channel width is used. This opens the question of which width measured in the field corresponds to the theoretical value, and when does a model such as the one developed here apply? In the Rio Torto, channel width is equal to valley width for the reaches with highest uplift rates [Whittaker et al., 2007a]. Whittaker et al. [2007b] report decreasing valley width for the Valleluce River in the downstream direction and suggest that erosive power is determined by valley width in this stream. Brocard and van der Beek [2006] hypothesized that the valley width reflects the frequency of strath erosion, and the ratio of channel width to valley width decreases as lateral erosion occurs more frequently. Lateral erosion is more important during floods [Hartshorn et al., 2002] and when sediment is abundant in the channel [Hancock and Anderson, 2002; Turowski et al., 2008a, 2008b]. Therefore, the ratio of channel to valley width seems to be closely related to discharge variability and sediment supply. To rigorously assess the different roles of channel and valley width needs a modeling framework that includes the effect of sediment and the flood cycle on channel geometry. In addition, the role of substrate properties and of weathering on channel development and strath formation needs to be better understood [cf. Montgomery, 2004; Wohl, 2008].

\section{Conclusions}

[47] To investigate the discrepancy between theoretical predictions of bedrock channel response to tectonic uplift and functional forms observed in experiments and nature, we have constructed a numerical model simulating the evolution of the cross section of a detachment-limited channel. As did previous models [Stark, 2006; Wobus et al., 2006, 2008], our effort has reproduced scaling relationships of channel geometry with discharge as often observed in nature. In contrast to an earlier model with a freely developing cross section [Wobus et al., 2006, 2008], we have included an erosion threshold in our model formulation. This has led to the prediction of a threshold-dominated response domain at low uplift rates, in which all channel parameters are approximately independent of uplift rate. Moreover, we have treated the channel bed slope as a dependent parameter rather than a boundary condition, which has given rise to slightly higher exponents in the width-discharge relation. However, as our model is similar in many ways to the one presented by Wobus et al. [2006, 2008], similar limitations apply. In particular, we have not explicitly modeled sediment transport and its effects on erosion.

[48] We find that the inclusion of an erosion threshold leads to a width-to-depth ratio dependent on uplift rate, erodibility and critical shear stress. This contradicts the assumption of Finnegan et al. [2005] that the width-todepth ratio is constant for a given channel type. Since Finnegan et al.'s [2005] original hypothesis has been tested against a very limited data set especially for bedrock channels, our study highlights the need for the collection of further field data in a wide range of different settings.

[49] All model results are traced closely by an analytical model based on the assumption of minimized energy expenditure in steady state channel cross sections [Lague et al., 2005b; Turowski et al., 2007]. Although this convergence lends some credibility to optimization assumptions such as this one, we are still lacking a complete understanding of the physical processes driving the channel to the steady state geometry. We have used the analytical model to illustrate how local tectonics can alter the observed widthdischarge scaling and we compared predictions with field observations. For all but one stream (the Clearwater River, Washington State) the model fails to make predictions consistent with observations. The results imply that stream-power-based erosion models are too simple to de- 
scribe the processes in natural channels. Future modeling attempts should include the effects of sediment transport on erosion and a realistic flood cycle.

\section{Notation}

$A$ upstream drainage area, $\mathrm{m}^{2}$.

$A_{c}$ channel cross-sectional area, $\mathrm{m}^{2}$.

$A_{i}$ polygon area associated with point $i, \mathrm{~m}^{2}$.

a exponent in erosion law.

$b$ uplift rate-discharge exponent.

$C_{S}$ shape factor in equation describing channel bed slope.

$C_{W}$ shape factor in equation describing channel width.

$c$ uplift rate-discharge prefactor, $\mathrm{m}^{1-3 b} \mathrm{~s}^{b-1}$.

$D$ m flow depth.

$E$ erosion rate, $\mathrm{m} \mathrm{s}^{-1}$.

$g$ acceleration due to gravity, $\mathrm{m} \mathrm{s}^{-2}$.

$k_{d}$ prefactor hydraulic geometry (depth), $\mathrm{m}^{1-3 \delta} \mathrm{s}^{\delta}$.

$k_{e}$ prefactor in simple shear stress incision law, $\mathrm{kg}^{-a} \mathrm{~m}^{a+1} \mathrm{~s}^{2 a-1}$.

$k_{s} \quad$ prefactor hydraulic geometry (slope), $\mathrm{m}^{3 \theta} \mathrm{s}^{-\theta}$.

$k_{Q S}$ constant factor in erosion law, $\mathrm{kg} \mathrm{m}^{-(1+3 m)} \mathrm{s}^{-1}$.

$k_{v}$ prefactor hydraulic geometry (velocity), $\mathrm{m}^{1-3 \nu} \mathrm{s}^{\nu-1}$.

$k_{w}$ prefactor hydraulic geometry (width), $\mathrm{m}^{1-3 \omega} \mathrm{s}^{\omega}$.

$N$ Manning's roughness coefficient, $\mathrm{m}^{-1 / 3} \mathrm{~s}$.

n summation index.

$P_{w} \quad$ wetted perimeter, $\mathrm{m}$.

$P_{i} \quad$ polygon perimeter along the channel wall for point $i, \mathrm{~m}$.

$Q$ water discharge, $\mathrm{m}^{3} \mathrm{~s}^{-1}$.

$R_{h}$ hydraulic radius, $\mathrm{m}$.

$S$ channel bed slope.

$\Delta t$ time step, s.

$U$ uplift rate, $\mathrm{m} \mathrm{s}^{-1}$.

$V$ flow velocity averaged over channel cross section, $\mathrm{m} \mathrm{s}^{-1}$.

$\mathbf{v}_{\mathbf{m}}$ vector along line $\mathbf{m} /$ vector of merged line.

$\mathbf{v}_{\mathbf{n}}$ vector along line $\mathbf{n} /$ vector of lines to be merged.

$W$ flow width, $\mathrm{m}$.

$w_{\mathbf{n}}$ weight of line $\mathbf{n}$.

$\delta \quad$ hydraulic geometry exponent (depth).

$\Theta$ stable hillslope angle.

$\theta$ hydraulic geometry exponent (slope).

$\eta \quad$ width-uplift rate exponent.

$\rho$ density of water, $\mathrm{kg} \mathrm{m}^{-3}$.

$\tau$ bed shear stress, $\mathrm{Pa}$.

$\tau_{c}$ critical shear stress, $\mathrm{Pa}$.

$\tau_{i}$ shear stress at point $i, \mathrm{~Pa}$.

$\nu$ hydraulic geometry exponent (velocity)

$\omega$ hydraulic geometry exponent (width).

[50] Acknowledgments. We are grateful to the many people who have commented on the work and concepts in this paper, in particular, J. R. Barbour, C. P. Stark, and A. C. Whittaker. Special thanks go to P. Meunier and D. Molenaar for suggestions on numerical routines. Thorough reviews by M. Attal, D. Burbank, and N. Gasparini helped to improve the paper. J.M.T. developed the numerical model at the University of Cambridge, supported by a NERC Blue Skies Studentship, the Cambridge Trusts, and the Cambridge Philosophical Society. The theoretical work, interpretation, and the writing of the manuscript were done at the WSL. Additional support came from the CNRS-INSU program RELIEFS. J.M.T. also thanks the Institute for Physics of Geological
Processes in Oslo, Norway, for funding a visit in 2005, during which this project was conceived and started.

\section{References}

Amos, C. B., and D. W. Burbank (2007), Channel width response to differential uplift, J. Geophys. Res., 112, F02010, doi:10.1029/2006JF000672.

Bagnold, R. A. (1977), Bedload transport by natural rivers, Water Resour Res., 13, 303-331, doi:10.1029/WR013i002p00303.

Brocard, G. Y., and P. A. van der Beek (2006), Influence of incision rate, rock strength, and bedload supply on bedrock river gradients and valleyflat widths: Field-based evidence and calibrations from western Alpine rivers (southeast France), in Tectonics, Climate, and Landscape Evolution, edited byS. D. Willet et al., Spec. Pap. Geol. Soc. Am., 398, 127-141, doi:10.1130/2006.2398(07).

Cowie, P. A., A. C. Whittaker, M. Attal, G. Roberts, G. E. Tucker, and A. Ganas (2008), New constraints on sediment-flux-dependent river incision: Implications for extracting tectonic signals from river profiles, Geology, 36, 535-538, doi:10.1130/G24681A.1.

Craddock, W. H., D. W. Burbank, B. Bookhagen, and E. J. Gabet (2007), Bedrock channel geometry along an orographic rainfall gradient in the upper Marsyandi River valley in central Nepal, J. Geophys. Res., 112, F03007, doi:10.1029/2006JF000589.

Diplas, P. (1990), Characteristics of self-formed straight channels, J. Hydrol. Eng., 116, 707-727, doi:10.1061/(ASCE)0733-9429(1990)116: $5(707)$.

Duvall, A., E. Kirby, and D. W. Burbank (2004), Tectonic and lithologic controls on bedrock channel profiles and processes in coastal California, J. Geophys. Res., 109, F03002, doi:10.1029/2003JF000086.

Fernandez Luque, R., and R. van Beek (1976), Erosion and transport of bed-load sediment, J. Hydraul. Res., 14, 127-144.

Finnegan, N. J., G. Roe, D. R. Montgomery, and B. Hallet (2005), Controls on the channel width of rivers: Implications for modelling fluvial incision of bedrock, Geology, 33(3), 229-232, doi:10.1130/G21171.1

Finnegan, N. J., L. Sklar, and T. K. Fuller (2007), Interplay of sediment supply, river incision, and channel morphology revealed by the transient evolution of an experimental bedrock channel, J. Geophys. Res., 112, F03S11, doi:10.1029/2006JF000569.

Gasparini, N. M., R. L. Bras, and K. X. Whipple (2006), Numerical modeling of non-steady-state river profile evolution using a sedimentflux-dependent incision model, in Tectonics, Climate, and Landscape Evolution, edited byS. D. Willet et al., Spec. Pap. Geol. Soc. Am., 398 , 127-141, doi:10.1130/2006.2398(08).

Hack, J. T. (1957), Studies of longitudinal stream profiles in Virginia and Maryland, U.S. Geol. Surv. Prof. Pap., 294, 45-80.

Hancock, G., and R. S. Anderson (2002), Numerical modeling of fluvial strath terrace formation in response to oscillating climate, Geol. Soc. Am. Bull., 114, 1131-1142.

Harbor, D. J. (1998), Dynamic equilibrium between an active uplift and the Sevier River, Utah, J. Geol, 106, 181-194, doi:10.1086/516015.

Hartshorn, K., N. Hovius, W. B. Dade, and R. L. Slingerland (2002), Climate-driven bedrock incision in an active mountain belt, Science, 297, 2036-2038, doi:10.1126/science.1075078.

Howard, A. D. (1994), A detachment-limited model of drainage basin evolution, Water Resour. Res., 30, 2261-2285, doi:10.1029/ 94WR00757.

Howard, A. D., and G. Kerby (1983), Channel changes in badlands, Geol. Soc. Am. Bull., 94, 739-752, doi:10.1130/0016-7606(1983)94< 739: $\mathrm{CCIB}>2.0 . \mathrm{CO} ; 2$

Huang, H. Q., H. H. Chang, and G. C. Nanson (2004), Minimum energy as the general form of critical flow and maximum flow efficiency and for explaining variations in river channel pattern, Water Resour. Res., 40, W04502, doi:10.1029/2003WR002539.

Humphrey, N. F., and S. K. Konrad (2000), River incision or diversion in response to bedrock uplift, Geology, 28, 43-46, doi:10.1130/00917613(2000)28<43:RIODIR >2.0.CO;2.

Jansen, J. D. (2006), Flood magnitude-frequency and lithologic control on bedrock river incision in post-orogenic terrain, Geomorphology, 82, 3957, doi:10.1016/j.geomorph.2005.08.018.

Johnson, J. P., and K. X. Whipple (2007), Feedbacks between erosion and sediment transport in experimental bedrock channels, Earth Surf. Processes Landforms, 32, 1048-1062, doi:10.1002/esp.1471.

Khodashenas, S. R., and A. Paquier (1999), A geometrical method for computing the distribution of boundary shear stress across irregular straight open channels, J. Hydraul. Res., 37, 381-388.

Knight, D. W., and H. S. Patel (1985), Boundary shear in smooth rectangular ducts, J. Hydrol. Eng., 111, 29-47, doi:10.1061/(ASCE)07339429(1985)111:1(29)

Knight, D. W., J. D. Demetriou, and M. E. Hamed (1984), Boundary shear in smooth rectangular channels, J. Hydrol. Eng., 110, 405-422, doi:10.1061/(ASCE)0733-9429(1984)110:4(405). 
Lague, D., N. Hovius, and P. Davy (2005a), Discharge, discharge variability, and the bedrock channel profile, J. Geophys. Res., 110, F04006, doi:10.1029/2004JF000259.

Lague, D., J. M. Turowski, P. Davy, and N. Hovius (2005b), The width (and slope) of an incising river: Analytical solution and comparison with natural and experimental channels, Geophys. Res. Abstr., 7, 04876

Lavé, J., and J. P. Avouac (2001), Fluvial incision and tectonic uplift across the Himalayas of central Nepal, J. Geophys. Res., 106(B11), 26,56126,591, doi:10.1029/2001JB000359.

Leopold, L. B., and T. Maddock Jr. (1953), The hydraulic geometry of stream channels and some physiographic implications, U.S. Geol. Surv. Prof. Pap., 252, 57 pp.

Lundgren, H., and I. G. Jonsson (1964), Shear and velocity distribution in shallow channels, J. Hydraul. Eng. Div. Am. Soc. Civ. Eng., 1, 1-21.

Manning, R. (1891), On the flow of water in open channels and pipes, Trans. Inst. Civ. Eng., 20, 161-207.

Meyer-Peter, E., and R. Müller (1948), Formulas for bed-load transport, in Proceedings of the 2nd Meeting of the International Association for Hydraulic Structures Research, pp.39-64, Int. Assoc. of Hydraul. Eng. and Res., Delft, Netherlands.

Molnar, P. (2001), Climate change, flooding in arid environments, and erosion rates, Geology, 29, 1071-1074, doi:10.1130/0091-7613(2001) 029<1071:CCFIAE $>2.0$.CO;2.

Molnar, P., R. S. Anderson, G. Kier, and J. Rose (2006), Relationships among probability distributions of stream discharges in floods, climate, bed load transport, and river incision, J. Geophys. Res., 111, F02001, doi:10.1029/2005JF000310.

Montgomery, D. R. (2004), Observations on the role of lithology in strath terrace formation and bedrock channel width, Am. J. Sci., 304, 454-476, doi:10.2475/ajs.304.5.454

Montgomery, D. R., and K. B. Gran (2001), Downstream variations in the width of bedrock channels, Water Resour. Res., 37(6), 1841-1846, doi:10.1029/2000WR900393.

Park, C. C. (1977), World-wide comparison in hydraulic geometry exponents of stream channels: An analysis and some observation, J. Hydrol. Amsterdam, 33, 133-146, doi:10.1016/0022-1694(77)90103-2.

Parker, G. (1978a), Self-formed straight rivers with equilibrium banks and mobile bed. Part 1. The sand-silt river, J. Fluid Mech., 89, 109-125, doi:10.1017/S0022112078002499.

Parker, G. (1978b), Self-formed straight rivers with equilibrium banks and mobile bed. Part 2. The gravel river, J. Fluid Mech., 89, 127-146, doi:10.1017/S0022112078002505

Parker, G. (1990), Surface-based bedload transport relation for gravel rivers, J. Hydraul. Res., 28, 417-436.

Parker, G., P. R. Wilcock, C. Paola, W. E. Dietrich, and J. Pitlick (2007) Physical basis for quasi-universal relations describing bankfull hydraulic geometry of single-thread gravel bed rivers, J. Geophys. Res., 112, F04005, doi:10.1029/2006JF000549.

Pazzaglia, F. J., and M. T. Brandon (2001), A fluvial record of long-term steadystate uplift and erosion across the Cascadia Forearc High, western Washington State, Am. J. Sci., 301, 385-431, doi:10.2475/ajs.301.4-5.385.

Pearce, S. A., F. J. Pazzaglia, and M. C. Eppes (2004), Ephemeral stream response to growing folds, Geol. Soc. Am. Bull., 116, 1223-1239, doi:10.1130/B25386.1.

Pizzuto, J. E. (1991), A numerical method for calculating the distribution of boundary shear stress across irregular straight open channels, Water Resour. Res., 27, 2457-2466, doi:10.1029/91WR01469.

Robert, A. (2003), River Processes - An Introduction to Fluvial Dynamics, Oxford Univ. Press, New York.

Roberts, G. P., and A. M. Michetti (2004), Spatial and temporal variations in growth rates along active fault systems: An example from LazioAbruzzo, central Italy, J. Struct. Geol., 26, 339-376, doi:10.1016/ S0191-8141(03)00103-2.

Seidl, M. A., and W. E. Dietrich (1992), The problem of channel erosion into bedrock, in Functional Geomorphology, edited by K.-H. Schmid and J. DePloey, Catena Suppl., 23, 101-124.

Shepherd, R. C. (1972), Incised river meanders: Evolution in simulated bedrock, Science, 178, 409-411, doi:10.1126/science.178.4059.409.

Sklar, L., and W. E. Dietrich (2004), A mechanistic model for river incision into bedrock by saltating bed load, Water Resour. Res., 40, W06301, doi:10.1029/2003WR002496.

Sklar, L., and W. E. Dietrich (2006), The role of sediment in controlling steady-state bedrock channel slope: Implications of the saltation-abrasion incision model, Geomorphology, 82, 58-83, doi:10.1016/j.geomorph 2005.08.019

Snyder, N. P., K. X. Whipple, G. E. Tucker, and D. J. Merritts (2003a), Channel response to tectonic forcing: Field analysis of stream morphology and hydrology in the Mendocino triple junction region, northern California, Geomorphology, 53, 97-127, doi:10.1016/S0169$555 \mathrm{X}(02) 00349-5$
Snyder, N. P., K. X. Whipple, G. E. Tucker, and D. J. Merritts (2003b), Importance of a stochastic distribution of floods and erosion thresholds in the bedrock river incision problem, J. Geophys. Res., 108(B2), 2117, doi:10.1029/2001JB001655.

Stark, C. P. (2006), A self-regulating model of bedrock river channel geometry, Geophys. Res. Lett., 33, L04402, doi:10.1029/2005GL023193.

Stock, J. D., and D. R. Montgomery (1999), Geologic constraints on bedrock river incision using the stream-power law, J. Geophys. Res., 104, 4983-4993, doi:10.1029/98JB02139.

Tomkin, J. H., M. T. Brandon, F. J. Pazzaglia, J. R. Barbour, and S. D. Willett (2003), Quantitative testing of bedrock incision models for the Clearwater River, NW Washington State, J. Geophys. Res., 108(B6), 2308, doi:10.1029/2001JB000862.

Tucker, G. E. (2004), Drainage basin sensitivity to tectonic and climatic forcing: Implications of a stochastic model for the role of entrainment and erosion thresholds, Earth Surf. Processes Landforms, 29, 185-205, doi:10.1002/esp. 1020

Tucker, G. E., and K. X. Whipple (2002), Topographic outcomes predicted by stream erosion models: Sensitivity analysis and intermodel comparison, J. Geophys. Res., 107(B9), 2179, doi:10.1029/2001JB000162.

Turowski, J. M., D. Lague, A. Crave, and N. Hovius (2006), Experimental channel response to tectonic uplift, J. Geophys. Res., 111, F03008, doi:10.1029/2005JF000306.

Turowski, J. M., D. Lague, and N. Hovius (2007), Cover effect in bedrock abrasion: A new derivation and its implications for the modeling of bedrock channel morphology, J. Geophys. Res., 112, F04006, doi:10.1029/ 2006JF000697.

Turowski, J. M., N. Hovius, M.-L. Hsieh, D. Lague, and M.-C. Chen (2008a), Distribution of erosion across bedrock channels, Earth Surf. Processes Landforms, 33, 353-363, doi:10.1002/esp.1559.

Turowski, J. M., N. Hovius, A. Wilson, and M.-J. Horng (2008b), Hydraulic geometry, river sediment and the definition of bedrock channels, Geomorphology, 99(1-4), 26-38, doi:10.1016/j.geomorph.2007.10.001. van der Beek, P., and P. Bishop (2003), Cenozoic river profile development in the upper Lachlan catchment (SE Australia) as a test of quantitative fluvial incision Models, J. Geophys. Res., 108(B6), 2309, doi:10.1029/ 2002JB002125

Vigilar, G. G., and P. Diplas (1997), Stable channels with mobile bed: Formulation and numerical solution, J. Hydraul. Eng., 123, 189-199, doi:10.1061/(ASCE)0733-9429(1997)123:3(189).

Whipple, K. X. (2004), Bedrock rivers and the geomorphology of active orogens, Annu. Rev. Earth Planet. Sci., 32, 151-185, doi:10.1146/annurev. earth.32.101802.120356

Whipple, K. X., and G. E. Tucker (1999), Dynamics of the stream-power river incision model: Implications for height limits of mountain ranges, landscape response timescales, and research needs, J. Geophys. Res., 104, 17,661 - 17,674, doi:10.1029/1999JB900120.

Whipple, K. X., and G. E. Tucker (2002), Implications of sediment-fluxdependent river incision models for landscape evolution, J. Geophys. Res., 107(B2), 2039, doi:10.1029/2000JB000044.

Whipple, K. X., G. S. Hancock, and R. S. Anderson (2000), River incision into bedrock: Mechanics and relative efficacy of plucking, abrasion, and cavitation, Geol. Soc. Am. Bull., 112, 490-503, doi:10.1130/00167606(2000)112<0490:RIIBMA>2.3.CO;2.

Whittaker, A. C., P. A. Cowie, M. Attal, G. E. Tucker, and G. P. Roberts (2007a), Bedrock channel adjustment to tectonic forcing: Implications for predicting river incision rates, Geology, 35, 103-106, doi:10.1130/ G23106A.1.

Whittaker, A. C., P. A. Cowie, M. Attal, G. E. Tucker, and G. P. Roberts (2007b), Contrasting transient and steady-state rivers crossing active normal faults: New field observations from the central Apennines, Italy, Basin Res., 19, 529-556, doi:10.1111/j.1365-2117.2007.00337.x.

Wobus, C. W., G. E. Tucker, and R. S. Anderson (2006), Self-formed bedrock channels, Geophys. Res. Lett., 33, L18408, doi:10.1029/ 2006GL027182.

Wobus, C. W., J. W. Kean, G. E. Tucker, and R. S. Anderson (2008) Modeling the evolution of channel shape: Balancing computational efficiency with hydraulic fidelity, J. Geophys. Res., 113, F02004, doi:10.1029/2007JF000914.

Wohl, E. E. (2000), Mountain Rivers, Water Resour. Monogr. Ser. vol. 14, AGU, Washington, D. C.

Wohl, E. E. (2008), The effect of bedrock jointing on the formation of straths in the Cache la Poudre River drainage, Colorado Front Range, J. Geophys. Res., 113, F01007, doi:10.1029/2007JF000817.

Wohl, E. E., and G. C. L. David (2008), Consistency of scaling relations among bedrock and alluvial channels, J. Geophys. Res., 113, F04013, doi:10.1029/2008JF000989.

Wohl, E. E., and D. M. Merritt (2001), Bedrock channel morphology, Geol. Soc. Am. Bull., 113, 1205-1212, doi:10.1130/0016-7606(2001) $113<1205 \cdot \mathrm{BCM}>2.0 \cdot \mathrm{CO} \cdot 2$ 
Yang, C. T., C. C. S. Song, and M. J. Woldenberg (1981), Hydraulic geometry and minimum rate of energy dissipation, Water Resour. Res., 17(4), 1014-1018, doi:10.1029/WR017i004p01014.

N. Hovius, Department of Earth Sciences, University of Cambridge,

Downing Street, Cambridge CB2 3EQ, UK.
D. Lague, Géosciences Rennes, UMR 6118, CNRS, F-35042 Rennes, France.

J. M. Turowski, WSL Birmensdorf, Zürcherstrasse 111, CH-8903 Birmensdorf, Switzerland. (jens.turowski@wsl.ch) 